\title{
Cellular stress pathways in pediatric bone marrow failure syndromes: many roads lead to neutropenia
}

\author{
Taly Glaubach ${ }^{1-3}$, Alex C. Minella ${ }^{4}$ and Seth J. Corey ${ }^{1-3,5}$
}

The inherited bone marrow failure syndromes, like severe congenital neutropenia (SCN) and Shwachman-Diamond syndrome (SDS), provide unique insights into normal and impaired myelopoiesis. The inherited neutropenias are heterogeneous in both clinical presentation and genetic associations, and their causative mechanisms are not well established. SCN, for example, is a genetically heterogeneous syndrome associated with mutations of ELANE, HAX1, GFI1, WAS, G6PC3, or CSF3R. The genetic diversity in $\mathrm{SCN}$, along with congenital neutropenias associated with other genetically defined bone marrow failure syndromes (e.g., SDS), suggests that various pathways may be involved in their pathogenesis. Alternatively, all may lead to a final common pathway of enhanced apoptosis. The pursuit for a more complete understanding of the molecular mechanisms that drive inherited neutropenias remains at the forefront of pediatric translational and basic science investigation. Advances in our understanding of these disorders have greatly increased over the last 10 years concomitant with identification of their genetic lesions. Emerging themes include induction of the unfolded protein response (UPR), defective ribosome assembly, and p53-dependent apoptosis. Additionally, defects in metabolism, disruption of mitochondrial membrane potential, and mislocalization have been found. When perturbed, each of these lead to an intracellular stress that triggers apoptosis in the vulnerable granulocytic precursor.

$I^{\mathrm{n}}$

neffective hematopoiesis is characterized as peripheral cytopenia(s) with a cellular bone marrow and has been applied commonly to describe myelodysplastic syndromes (MDS). The majority of inherited bone marrow failure syndromes display ineffective hematopoiesis, and they frequently terminate in secondary MDS or acute myeloid leukemia (AML). The inherited bone marrow failure syndromes are both multilineage (Fanconi anemia, dyskeratosis congenita, and ShwachmanDiamond syndrome (SDS)) and predominantly single lineage (severe congenital neutropenia (SCN), Diamond-Blackfan anemia (DBA), and congenital amegakaryocytic thrombocytopenia) disorders. Most of these disorders also involve organs besides the blood, most frequently the skin, skeleton, kidney, and gastrointestinal tract. Genetic lesions have been identified for all of these syndromes, although not all patients with these disorders have a known genetic cause. The inherited bone marrow failure syndromes offer genetically defined experiments of nature that provide unique opportunities for studying and understanding the regulatory networks involved in hematopoiesis and how perturbations in blood cell function result in marrow production failure and peripheral cytopenias. Here, we review the most recent developments in molecular basis of inherited bone marrow failure syndromes, particularly $\mathrm{SCN}$. One emerging theme is that different pathways involving cellular stress mechanisms drive apoptosis of blood cell precursors, resulting in cytopenia(s). These stress mechanisms include endoplasmic reticulum (ER) stress and the unfold protein response, defective ribosome assembly, and induction of the p53 pathway.

\section{INSIGHTS INTO SCN FROM ITS GENETIC HETEROGENEITY}

Once known as Kostmann syndrome, $\mathrm{SCN}$ is characterized as profound neutropenia (typically less than $200 / \mu \mathrm{l}$ ), which presents in the first several months of life. Other forms of neutropenia may be mild (between 1,500 and $500 / \mu l$ ) or moderate

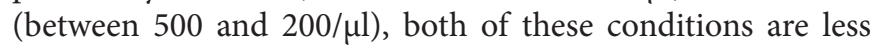
likely to be associated with life-threatening infections. Bone marrow examination of patients with SCN shows an arrest at the promyelocyte stage in granulopoiesis. The introduction of filgrastim in the 1990s markedly improved the survival and quality of life, effectively removing major morbidity and frequent mortality due to infections. As the life span of patients with SCN increased, so did the frequency of transformation to secondary MDS/AML $(1,2)$.

Using genetic linkage analysis and positional cloning, Horwitz et al. (3) discovered that heterozygous, dominantly inherited mutations in neutrophil elastase were found in all patients with cyclic neutropenia. Cyclic neutropenia is phenotypically distinct from SCN. Profound neutropenia arises periodically (classically every $21 \mathrm{~d}$ ), and it is diagnosed more commonly during adolescence and adulthood. Moreover, it is not associated with transformation to secondary MDS/AML.

\footnotetext{
'Department of Pediatrics, Northwestern University Feinberg School of Medicine, Chicago, Illinois; ${ }^{2}$ Division of Hematology, Oncology and Stem Cell Transplantation, Ann \& Robert H. Lurie Children's Hospital of Chicago, Chicago, Illinois; ${ }^{3}$ Robert H. Lurie Comprehensive Cancer Center, Northwestern University, Chicago, Illinois; ${ }^{4}$ Department of Medicine, Division of Hematology-Oncology, Northwestern University Feinberg School of Medicine and Robert H. Lurie Comprehensive Cancer Center, Chicago, Illinois; ${ }^{5}$ Department of Cell \& Molecular Biology, Northwestern University Feinberg School of Medicine, Chicago, Illinois. Correspondence: Seth J. Corey (coreylab@yahoo.com)

Received 2 May 2013; accepted 16 September 2013; advance online publication 8 January 2014. doi:10.1038/pr.2013.197
} 
Shortly after the mutation in neutrophil elastase gene was discovered, it was also found to occur in a majority of children with SCN. Once known as ELA2, the gene is now named ELANE. That the same mutation may be found in either SCN or cyclic neutropenia challenges our understanding of genotypephenotype relationships. The molecular basis for this phenotype diversity is unknown; possibilities include the presence of another genetic lesion, single-nucleotide polymorphisms as modifiers, and epigenetic misprogramming.

$\mathrm{SCN}$ is genetically heterogeneous, and other genetic mutations have been found in small groups of patients (Table 1). A growing list of monogenic mutations have been identified: the mitochondrial protein Hax-1, the transcription factor Gfi-1 (4), the cytoskeletal protein Wiskott-Aldrich syndrome protein (5), the enzyme glucose-6-phosphatase, subunit 3 (G6PC3) (6), and the granulocyte colony-stimulating factor (GCSF) receptor (7). Other causes of moderate to severe inherited neutropenias are mutations in the phospholipase transacylase tafazzin in Barth syndrome (8), lysosomal trafficking regulator in Chediak-Higashi syndrome (9), the clathrin-associated AP3B1 in type 2 Hermansky-Pudlak syndrome (10), the endosomal protein p14 (11), the serine/threonine kinase STK4 (12), the sorting protein Vps45 $(13,14)$, the chemokine receptor CXCR4 in WHIM (warts, hypogammaglobulinemia, infections, and myelokathexis) syndrome (15), the ribosomeassociated protein Shwachman-Bodian-Diamond syndrome (SBDS) in SDS (16), and the transcription factor GATA2 in MonoMAC syndrome (17). All of these widely variant genetic disorders appear to result in enhanced or accelerated apoptosis of granulocyte precursors, such as the promyelocyte.

Involved in $\sim 60 \%$ of patients with SCN, ELANE encodes neutrophil elastase, an enzyme synthesized in neutrophil precursors as a propeptide and then packaged into granules as the mature, active enzyme. Mutations in more than 80 different sites distributed over the 5 exons and introns have been isolated from patients with $\mathrm{SCN}$, although most have clustered in exon 2 (18). One hypothesis states that the mutation alters the propeptide cleavage sites, leading to mislocalization

Table 1. Characteristics of genetically defined neutropenias

\begin{tabular}{|c|c|c|c|c|c|c|}
\hline Condition & $\begin{array}{l}\text { Affected } \\
\text { genes }\end{array}$ & $\mathrm{ANC} / \mu \mathrm{l}$ & $\begin{array}{c}\text { Mode of } \\
\text { transmission }\end{array}$ & Functionality & $\begin{array}{l}\text { Distinguishing features and } \\
\text { clinical associations }\end{array}$ & Bone marrow findings \\
\hline \multirow[t]{6}{*}{ SCN } & ELANE & $\begin{array}{l}\text { Usually } \\
<200\end{array}$ & $\begin{array}{l}\text { Autosomal } \\
\text { dominant }\end{array}$ & Variable & None known & $\begin{array}{l}\text { Granulocyte maturation arrest at } \\
\text { promyelocyte/myelocyte stage }\end{array}$ \\
\hline & HAX-1 & & $\begin{array}{l}\text { Autosomal } \\
\text { recessive }\end{array}$ & Loss of function & $\begin{array}{l}\text { Seizures, mild-severe cognitive } \\
\text { deficits, developmental delay }\end{array}$ & \\
\hline & GFI1 & & $\begin{array}{l}\text { Autosomal } \\
\text { dominant }\end{array}$ & Loss of function & Monocytosis, lymphopenia & \\
\hline & WAS & & X-linked & $\begin{array}{l}\text { Gain of } \\
\text { function }\end{array}$ & $\begin{array}{l}\text { Monocytopenia, lymphopenia, } \\
\text { low natural killer cells, } \\
\text { hypogammaglobulinemia }\end{array}$ & \\
\hline & G6PC3 & & $\begin{array}{l}\text { Autosomal } \\
\text { recessive }\end{array}$ & Loss of function & $\begin{array}{l}\text { Structural heart disease, } \\
\text { urogenital malformations, } \\
\text { prominent superficial veins }\end{array}$ & \\
\hline & GCSFR & & $\begin{array}{l}\text { Autosomal } \\
\text { dominant }\end{array}$ & Loss of function & $\begin{array}{l}\text { Mutations in extracellular } \\
\text { domain when germline; high risk } \\
\text { for malignant transformation in } \\
\text { acquired nonsense mutations }\end{array}$ & \\
\hline CyN & ELANE & $\begin{array}{l}\text { Variable } \\
\text { and cyclic }\end{array}$ & $\begin{array}{l}\text { Autosomal } \\
\text { dominant }\end{array}$ & Variable & $\begin{array}{l}\text { None known; no increased risk of } \\
\text { malignant transformation }\end{array}$ & $\begin{array}{l}\text { Cyclic maturation arrest at } \\
\text { promyelocyte/myelocyte stage, } \\
\text { corresponding with the cycle of } \\
\text { peripheral counts }\end{array}$ \\
\hline SDS & SBDS & Variable & $\begin{array}{l}\text { Autosomal } \\
\text { recessive }\end{array}$ & Loss of function & $\begin{array}{l}\text { Failure to thrive, pancreatic } \\
\text { exocrine dysfunction, skeletal } \\
\text { dysplasia } \pm \text { anemia }\end{array}$ & $\begin{array}{l}\text { Variable cellularity, complete } \\
\text { maturation of granulocytic } \\
\text { lineage }\end{array}$ \\
\hline $\begin{array}{l}\text { WHIM } \\
\text { syndrome }\end{array}$ & CXCR4 & Moderate & $\begin{array}{l}\text { Autosomal } \\
\text { dominant }\end{array}$ & Loss of function & $\begin{array}{l}\text { Warts, } \\
\text { hypogammaglobulinemia, } \\
\text { recurrent infections, and } \\
\text { myelokathexis }\end{array}$ & $\begin{array}{l}\text { Complete granulocyte maturation } \\
\text { and cellularity; defect lies in failure } \\
\text { of granulocytes to leave the } \\
\text { marrow }\end{array}$ \\
\hline $\begin{array}{l}\text { Barth } \\
\text { syndrome }\end{array}$ & $\mathrm{TAZ}$ & Moderate & X-linked & Loss of function & $\begin{array}{l}\text { Cardiomyopathy, defect in } \\
\text { tafazzin which is involved in } \\
\text { phospholipid turnover }\end{array}$ & $\begin{array}{l}\text { Complete granulocyte } \\
\text { maturation }\end{array}$ \\
\hline $\begin{array}{l}\text { Hermansky- } \\
\text { Pudlak, type } 2\end{array}$ & AP3B1 & Variable & $\begin{array}{l}\text { Autosomal } \\
\text { recessive }\end{array}$ & Loss of function & $\begin{array}{l}\text { Oculocutaneous albinism, } \\
\text { bleeding diathesis }\end{array}$ & $\begin{array}{l}\text { Complete granulocyte } \\
\text { maturation }\end{array}$ \\
\hline $\begin{array}{l}\text { MonoMAC } \\
\text { syndrome }\end{array}$ & GATA2 & $\begin{array}{l}\text { Mild- } \\
\text { moderate }\end{array}$ & $\begin{array}{l}\text { Autosomal } \\
\text { dominant }\end{array}$ & Loss of function & $\begin{array}{l}\text { Myelodysplasia, monocytopenia, } \\
\text { warts, NK cell dysfunction }\end{array}$ & $\begin{array}{l}\text { Myelodysplasia, complete } \\
\text { granulocyte maturation }\end{array}$ \\
\hline
\end{tabular}

ANC, absolute neutrophil count; CyN, cyclic neutropenia; NK, natural killer; SCN, severe congenital neutropenia; SDS, Shwachman-Diamond syndrome; WHIM, warts, hypogammaglobulinemia, infections, myelokathexis. 


\section{Mechanisms of inherited neutropenia $\quad$ Review}

and/or inappropriate activation prior to its compartmentalization. The mislocalization causes injury to the neutrophil precursors and prevents their survival and complete maturation to granulocytes. However, these diverse mutations also share the increased tendency to misfold, induce ER stress, and the unfolded protein response (UPR).

Altered expression of Bcl-2 family members (19) or cytoplasmic accumulation of a misfolded protein and induction of the UPR can accelerate apoptosis in granulocyte precursers (20-22). Compelling evidence comes from recent in vivo studies in mice (23). To test the hypothesis that UPR impairs granulocyte precursor survival and differentiation, a knock-in mice strain was created to express a common missense mutation in ELANE found in patients with SCN. This mutation results in a truncated neutrophil elastase protein, which has lost the ability to form a C-terminal disulfide bond important for proper protein folding. Unlike prior studies where the misfolded protein accumulates, this protein is rapidly degraded. Despite a mild increase in basal UPR activation, the mice did not display significantly enhanced expression of genes associated with UPR activation and had normal and stress granulopoiesis, with normal ability to repopulate the bone marrow after both chemotherapy induced myelosuppression and by competitive repopulation assays. However, when treated with tunicamycin (which inhibits glycosylation and induces ER stress), the mutant ELANE cells displayed a drop in viability and impaired differentiation. Treatment of mutant Elane mice with a single dose of bortezomib, a proteosome inhibitor that suppresses the compensatory ER-associated degradation pathway, resulted in marked neutropenia along with associated enhancement of UPR activation genes. Although they did not show a corresponding increase in mutant Elane protein (i.e., decreased degradation) by western blot, these studies provide additional support for pathogenic role of ER stress and the UPR in ELANE-associated neutropenia.

Alternatively, some have suggested that apoptosis results from mislocalization of the mutant protein. The neutrophil elastase contains a posttranslationally cleaved N-terminal signal sequence, which directs it to insertion into the ER. Mistrafficking occurs when the mutant protein fails to be packaged into the lysosomal granules that are so critical for neutrophil function (21). A subset of genes associated with neutropenia is indeed associated with the cytoskeleton or endocytic pathways (see above). In particular, AP3B1 binds to neutrophil elastase. Thus, it has been argued that mutations in either ELANE or in an associated protein results in mislocalization of neutrophil elastase and as yet undefined injury to the maturing granulocyte precursor (24). However, neither the UPR or mislocalization hypotheses explain why pharmacologic doses of GCSF correct the neutropenia. GCSF not only induces lineage commitment and drives granulocyte differentiation, but it also promotes neutrophil activity and survival $(25,26)$.

Another subset of genetic disorders resulting in moderate to severe neutropenia involves metabolic pathways. An autosomal-recessive, syndromic form of SCN characterized by $\mathrm{SCN}$, structural heart disease, urogenital malformations, and prominent superficial venous ectasia was first characterized in 2009 (6). Whole-genome genotyping and linkage analysis was performed on two consanguineous families containing a total of five children with SCN, all without ELANE or HAX1 mutations. Sequencing of the candidate gene G6PC3, which encodes the glucose-6-phosphatase, catalytic subunit 3, revealed a homozygous missense mutation in all five children and heterozygous mutations in all parents. All mutations resulted in complete loss of function of the enzymatic activity of glucose-6-phosphatase. Distinct homozygous GCPC3 mutations were found in another six patients with syndromic SCN. Previous to this discovery, chronic neutropenia was observed in patients with glycogen storage disease type 1 (von Gierke's disease) caused by functional deficiency of glucose-6-phosphatase either by mutation of G6PC itself (type 1a) or its transporter (type 1b). Both lead to impairment of gluconeogenesis and glycogenolysis; however, neutropenia and neutrophil dysfunction are hallmarks of type $1 \mathrm{~b}$ and are only rarely seen in type 1a. Neutrophils from patients with type $1 \mathrm{~b}$ glycogen storage disease display apoptotic signatures: exposure of phosphatidylserine on the cell surface, caspase activity, and translocation of proapoptotic Bax protein (27). To assess the functional consequences of the novel G6PC3 mutations, the investigators expressed either wild-type or mutant G6PC3 in yeast and demonstrated decreased enzymatic hydrolysis activity in the mutant cells. Peripheral blood neutrophils from these patients displayed markedly enhanced apoptosis after treatment with tunicamycin or tumor necrosis factor (TNF)- $\alpha$ compared to neutrophils of healthy controls. Sensitivity to apoptosis in $\mathrm{CD} 34^{+}$cells isolated from two of these patients was rescued by expression of wild-type GCPC3. Electron microscopy demonstrated enlargement of the rough ER in bone marrow myeloid progenitors of four patients compared with normal controls, which could indicate ER stress. Additionally, neutrophil whole cell lysates from two patients demonstrated enhanced phosphorylation of GSK-3 $\beta$ and MCl-1, suggesting that this Akt-dependent pathway might be involved. Deprivation of glucose enhanced apoptosis of both wild-type and G6PC3-deficient neutrophils. Administration of GCSF corrected the neutropenia and was associated with increased glucose uptake and elevated intracellular levels of G6P, lactate, and adenosine-5'-triphosphate. These results support a role for GCSF in supporting critical neutrophil metabolism (28). In Barth syndrome, boys suffer from cardiomyopathy, poor musculoskeletal development, and neutropenia. The defect is due to mutation in TAZ, which encodes tafazzin, a mitochondrial phospholipid transacylase. As a result, there is mitochondrial dysfunction due to abnormal cardiolipin accumulation and cristae morphology $(29,30)$.

Originally described in Sweden by Rolf Kostmann in 1956 as an autosomal recessive disorder that he called infantile agranulocytosis (31), those affected patients are now known to carry a mutation in HAX1. HAX1 encodes the hematopoietic cell-specific Lyn substrate 1 (HCLS1)-associated protein X-1, a mitochondrial-associated antiapoptotic protein critical for maintaining the inner mitochondrial membrane potential and protecting myeloid cells from apoptosis (32). HAX1 mutations 


\section{Review $\mid$ Glaubach e tal.}

are typically nonsense mutations resulting in premature stop codons and loss of function, often with complete loss of protein expression. The severe neutropenia is often associated with neurologic and neurocognitive deficits, particulary if the mutation affects both HAX-1 isoforms (33).

Functional studies demonstrate accelerated apoptosis in the bone marrow of HAX1-deficient patients, along with a selective decrease in $\mathrm{Bcl}-2$ expression in myeloid progenitor cells. Treatment with GCSF restores Bcl-2 expression, partially reverses cytochrome $c$ release, and improves survival of myeloid progenitor cells (19). These studies suggest a role for mitochondria-dependent apoptosis and provide another potential mechanism for the benefit of GCSF treatment. Additional insights have come from recent work demonstrating interactions between HAX-1, HCLS1 and transcription factor lymphoid-enhancer-binding factor 1 (LEF-1) proteins, and their essential role in GCSF-mediated granulopoiesis (34). LEF-1 activates C/EBPa, a critical transcription factor required for granulopoiesis. Patients with HAX1 mutations have profound downregulation of LEF-1 and its downstream target genes $(35,36)$. Most recently, the same group demonstrated that GCSF stimulates HCLS1 phosphorylation and binding to LEF-1, allowing both nuclear translocation and autoregulation of LEF-1. Loss of HAX1 inhibits GCSF-mediated myelopoiesis by inhibiting phosphorylation of HCLS1 and subsequent LEF-1 expression with associated decreased colony forming potential. Furthermore, blasts of most patients with AML displayed high levels of both GCSF and HCLS1. Knockdown of HCLS1 or LEF-1 inhibited their proliferative capacity and induced apoptosis. Altogether, this advances another mechanism by which GCSF ameliorates neutropenia in patients with SCN.

Although each of these genetically defined causes of SCN provides clues to the mechanisms that converge on a common apoptotic pathway, one must recognize the possibility of a more complex process. For example, four patients with concurrent mutations in two of these genes have been described (one patient with ELANE+HAX1, one with ELANE+G6PC3, and two with $H A X 1+G 6 P C 3)$, challenging mutation analysis algorithms in SCN (37). We also have a patient with severe neutropenia and anemia with mutations in SBDS and HAX1 (38). Although this may represent a minor subset of patients, it highlights the potential role for multiple gene interactions. It raises the possibility of one mutation being permissive rather than a causative driver, or creating a complex interaction of biochemical aberrations culminating in the clinical phenotype, rather than a simple reductionist approach.

\section{RIBOSOMOPATHIES: DBA, SDS, AND DEL (5q) SYNDROME}

DBA, an inherited bone marrow failure syndrome characterized by severe hypoplastic macrocytic anemia, was the first disease to be linked to loss of function of ribosomal proteins and initially attributed to mutations in the RPS19 gene, which encodes a ribosomal protein critical for maturation of the $40 \mathrm{~S}$ ribosomal subunit $(39,40)$. Numerous other ribosomal genes have subsequently been identified in clinical presentations of
DBA, including RPS24, RPS17, RPL35A, RPL11, and others $(41,42)$. Haploinsufficiency in these genes thus impairs normal ribosomal biogenesis, and importantly, induces expression and activity of p53 $(43,44)$. TP53 (encoding the p53 protein) is a tumor suppressor gene known as "the gatekeeper of the genome" due to its critical role in regulating cell proliferation and survival in response to genotoxic and oncogenic stressors. Additionally, p53 serves an important role in the surveillance of protein translation (45). Expression of the p53 protein is regulated largely at the posttranslational level by ubiquitinmediated proteolysis, and in particular, by the $\mathrm{Mdm} 2$ ubiquitin ligase. Perturbations in ribosome biogenesis (either by inadequate rRNA transcription, disruption of rRNA processing, or ribosomal protein imbalance) are associated with induction of nucleolar stress and activation of the p53 pathway, resulting in enhanced cell cycle arrest and apoptosis (46). In particular, the rRNA processing defects in DBA result in accumulation of free ribosomal proteins, including RPL11, that can bind and inhibit Mdm2, stabilizing p53 $(40,43,44,47)$. Notably, the erythroid maturation defects associated with RPS19 are rescued by inhibition of p53, pointing to a pathogenic role for p53 activation in the setting of ribosomal protein mutation-associated dyserythropoiesis.

A handful of other congenital disorders have been linked to defective ribosome biogenesis or function and have been grouped in a class known as the ribosomopathies. One of these is SDS, an inherited bone marrow failure syndrome classically characterized by neutropenia, exocrine pancreatic dysfunction, and skeletal dysplasia. The affected gene, SBDS, is highly conserved. Its ortholog in yeast ( $S d o l)$ has been well studied and is critical for ribosome maturation (48). Still, its precise role(s) in mammalian physiology is incompletely known. In addition to its association with ribosomes, other roles for SBDS include regulating Fas-mediated apoptosis, stabilization of the mitotic spindle, DNA repair, and ER stress $(49,50)$. Eukaryotic initiation factor 6 (eIF6), also known as the antiassociation factor, binds to the large preribosomal subunit during ribosome biogenesis preventing premature association with the small subunit. Removal of eIF6 is then required for late cytoplasmic maturation of the $60 \mathrm{~S}$ subunit as it blocks the interunit bridge formation between the $40 \mathrm{~S}$ and $60 \mathrm{~S}$ subunits. In contrast to the model in yeast, eIF6 release in mammalian cells was mediated by phosphorylation at Ser325 by activated protein kinase C (51). However, a recent elegant study challenges the previous mammalian model and directly demonstrates the requirement of SBDS in mammalian ribosomal maturation and establishes SDS as a ribosomopathy (52). By isolating the late cytoplasmic $60 \mathrm{~S}$ ribosomal subunit from conditional SBDS knockout mice, these studies demonstrate that SBDS and the GTPase EFL1 (elongation factor like 1) are necessary and directly cooperate to catalyze eIF6 release, which is guanosine triphosphate dependent and independent of eIF6 Ser235 phophorylation. As predicted, SBDS deletion also causes subunit joining defect and accumulation of late cytoplasmic pre-60S ribosomes. Functional analysis of common missense mutations found in SDS demonstrates the essential role of SBDS in coupling guanosine triphosphate hydrolysis with 


\section{Mechanisms of inherited neutropenia $\quad$ Review}

eIF6 release. Altogether, this firmly establishes a role of SBDS in mammalian translational activation of ribosomes.

In contrast to the genetically well-defined inherited marrow failure syndromes, the MDS are a heterogeneous group of clonal bone marrow neoplasms characterized by ineffective hematopoiesis and variable degrees of peripheral cytopenias. Pediatric MDS is most often secondary and occurs as a complication of a known or undiagnosed bone marrow failure state or genotoxic therapy (chemotherapy or radiation). Patient bone marrow displays variable degrees of cellularity. In contrast, adult MDS is thought to be de novo in older individuals whose marrows are most often hypercellular. In most cases of primary MDS, the underlying genetic lesion is unknown, and the phenotypic heterogeneity of the disorder imposes challenges to its investigation and generalizability. Various theories of pathogenesis have emerged, including the diseased stem cell niche. Interestingly, the loss of $S b d s$ in murine osteoprogenitors results in myelodysplasia, similar to results obtained from culturing blood stem cells with stroma derived from patients with SDS $(53,54)$.

The deletion $5 \mathrm{q}$ (del (5q) or 5q-) syndrome, a distinct entity within the spectrum of low-risk MDS, is also now recognized as a ribosomopathy $(55,56)$. The del $(5 q)$ syndrome is defined by the interstitial deletion of a large region in the long arm of chromosome 5 and characterized by a macrocytic refractory anemia, variable neutropenia, and often thrombocytosis with dysplastic megakaryocytes. It is rarely seen in children $(57,58)$. Additional genetic analysis of the common deleted region of $5 q$ revealed several candidate genes; however, gene sequencing did not demonstrate any mutations, suggesting that the pathogenesis lies in allelic haploinsufficiency. The gene for RPS14, component of the small ribosomal 40S subunit, is located in this common deleted region, and an RNAi screen of CD $34^{+}$cells identified RPS14 as a culprit (59). Forced haploinsufficiency of RPS14 in normal CD34 ${ }^{+}$cells induced activation of $\mathrm{p} 53$ and recapitulated the erythroid maturation arrest that characterizes both del (5q) syndrome and DBA. Forced expression of RPS14 in patient derived del (5q) CD34 ${ }^{+}$ cells rescued the disease phenotype. Furthermore, haploinsufficiency of RPS14 leads to a block in preribosomal RNA processing that links the molecular basis of del (5q) syndrome to other congenital disorders of ribosome biogenesis, such as DBA. However, this mechanism alone does not account for the other stereotypical features of the del (5q) syndrome (variable neutropenia, dysplastic megakaryopoeisis, and thrombocytosis). Like DBA, p53 activation appears to play a causative role in bone marrow disease phenotypes associated with Rps14 mutation, as demonstrated in a mouse model of the $5 q$ deletion syndrome (60). Moreover, other haploinsufficient genes besides RPS14 likely contribute to phenotypes associated with the del (5q) syndrome $(60,61)$.

The traditional framework for thinking about disease causing gene mutations leading to altered or absent protein products continues to be challenged. Similar to the explosion of scientific inquiry that came with the emergence of ribosome dysfunction as a mechanism for impaired hematopoiesis, so have the investigation of epigenetic regulation and the role of noncoding DNA sequences in disease pathogenesis. In particular, microRNAs, small noncoding RNAs 22-25 nucleotides in length, function as posttranscriptional repressors by inhibiting the translation of their respective target mRNA. miRNA dysregulation has been implicated in a wide spectrum of disorders. Starczynowski et al. (61) elegantly demonstrated miR-145 and miR-146a haploinsufficiency as potential drivers of the $5 \mathrm{q}$ - phenotype not accounted for by RPS14 haploinsufficiency. Parallel sequencing of small RNA libraries from multiple cells lines with and without the $5 \mathrm{q}$ deletion identified 25 miRNAs located on chromosome $5 \mathrm{q}, 13$ of which map to the common deleted region, and 10 of which were highly expressed in bone marrow. Expression levels of miR-145 and miR-146a were significantly lower in both total bone marrow and isolated $\mathrm{CD} 34^{+}$cells from patients with del (5q) MDS as compared to that of cytogenetically normal MDS and normal controls. When mouse hematopoietic stem cells with miR-145 and miR-146a knocked down were transplanted into lethally irradiated mice along with competitor wild-type cells, the developed the features of the del (5q) syndrome: peripheral thrombocytosis, variable neutropenia, decreased myeloid colony formation, and increased megakaryocyte colony formation with dysplasia. Toll-interleukin-1 receptor domaincontaining adaptor protein (TIRAP) and tumor necrosis factor receptor-associated factor-6 (TRAF6) were identified as targets of miR-145 and miR-146a, respectively. The authors go on to convincingly demonstrate that:

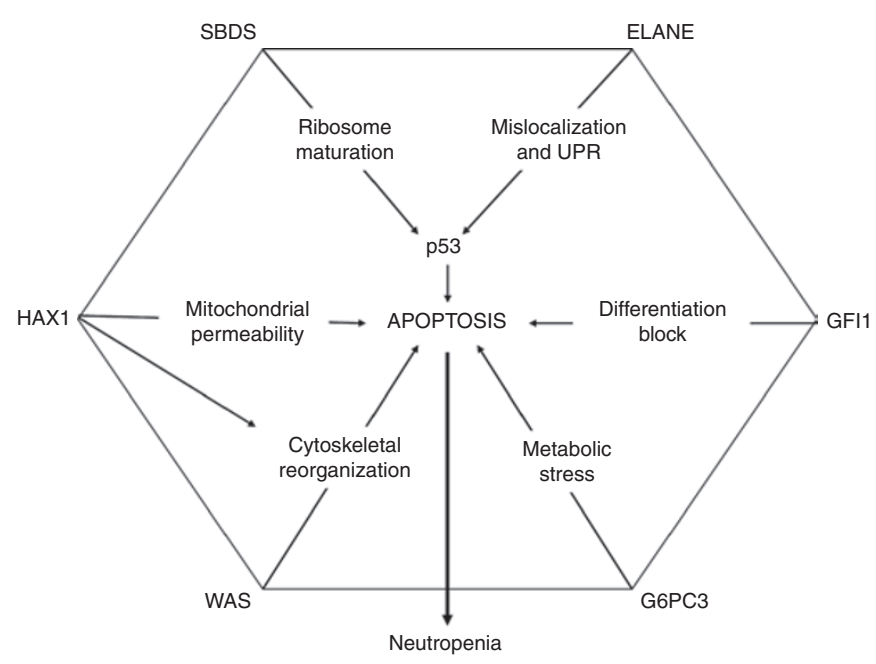

Figure 1. Pathway relationships among genetically defined neutropenias. The most common cause of severe congenital neutropenia (SCN) is ELANE mutation. Some forms of SCN are syndromic (e.g., those involving HAX1 and G6PC3). Some are associated with transformation to secondary myelodysplasia and acute myeloid leukemia (ELANE, HAX1, and WAS). Shwachman-Bodian-Diamond syndrome (SBDS) mutation results in Shwachman-Diamond syndrome, which is typically a mild to moderate neutropenia. The various genetic causes of congenital neutropenias lead mostly to apoptosis in either p53-dependent or p53-independent mechanisms. Not discussed in this review article is differentiation arrest due to mutations in GFI1 (64) or cytoskeletal dysregulation of WAS (65). UPR, unfolded protein response. 
1. Expression levels of miR-145 and miR-146a are inversely proportional to the expression levels of their respective targets in a cell line model, mouse hematopoeitic stem/ progenitor cell (HSPC) and human CD34 ${ }^{+}$cells-an effect that is abrogated in all systems by mutation of the predicted miRNA binding sequence;

2. Toll-interleukin-1 receptor domain-containing adaptor protein directly activates TRAF6 via polyubiquination;

3. TIRAP activates NF- $\kappa \mathrm{B}$ via TRAF6;

4. Forced expression of TRAF6 alone also phenocopies the hematopoietic defects seen with miR-145 and miR-146a knockdown and resulted in progressive marrow failure or AML in one third of the transplanted mice;

5. TRAF6 induces expression of interleukin (IL)-6 and not TNF- $\alpha$;

6. The hematopoietic defects induced by forced expression of TRAF6 are IL-6 dependent in a paracrine fashion.

Furthermore, lenalidomide monotherapy is the first-line treatment for del (5q-). Although the precise mechanism of action of the drug is unknown, it has been shown to downregulate both TNF- $\alpha$ and IL-6. Thus, aberrant activation of innate immune responses and associated stress cytokines provide another pathway to impaired hematopoiesis.

\section{SUMMARY}

Moderate and SCNs are monogenic disorders due to mutations affecting a diverse range of intracellular processes. These involve cytoskeletal reorganization, mitochondrial integrity, and intracellular stress due to metabolic, UPR, mislocalization, and ribosomal biosynthetic defects (Figure 1). All seem to converge on a final common pathway involving apoptosis, with or without involvement of p53. Because the neutrophil is shortest lived circulating blood cell, perhaps it makes sense that it is so vulnerable to stress (62). Insights from these pediatric inherited disorders have helped to illuminate stress pathways and the potential for novel therapeutic strategies. Further understanding of the mechanism of disease and cooperating accessory pathways may provide a rationale for drug repurposing or novel synergistic combinations. Advances in our discovery and understanding of these pathways have also highlighted the potential for new drug development, such as selective inhibitors of the UPR or exogenous manipulation of its signaling pathways (63). Critical questions remain about the details of each proapoptotic process, what mechanisms are present in nonaffected tissues or cell lineages, the role of cytokines (such as GCSF) in promoting transformation to secondary MDS/AML, and how genetic and epigenetic factors contribute to the phenotype.

\section{STATEMENT OF FINANCIAL SUPPORT}

T.G. was supported by ASH Research Training Award and the MDS Foundation Young Investigator Grant.

Disclosure: The authors have no conflicts of interest.

\section{REFERENCES}

1. Donadieu J, Leblanc T, Bader Meunier B, et al.; French Severe Chronic Neutropenia Study Group. Analysis of risk factors for myelodysplasias, leukemias and death from infection among patients with congenital neutropenia. Experience of the French Severe Chronic Neutropenia Study Group. Haematologica 2005;90:45-53.

2. Rosenberg PS, Alter BP, Bolyard AA, et al.; Severe Chronic Neutropenia International Registry. The incidence of leukemia and mortality from sepsis in patients with severe congenital neutropenia receiving long-term G-CSF therapy. Blood 2006;107:4628-35.

3. Horwitz M, Benson KF, Person RE, Aprikyan AG, Dale DC. Mutations in ELA2, encoding neutrophil elastase, define a 21-day biological clock in cyclic haematopoiesis. Nat Genet 1999;23:433-6.

4. Person RE, Li FQ, Duan Z, et al. Mutations in proto-oncogene GFI1 cause human neutropenia and target ELA2. Nat Genet 2003;34:308-12.

5. Devriendt K, Kim AS, Mathijs G, et al. Constitutively activating mutation in WASP causes X-linked severe congenital neutropenia. Nat Genet 2001;27:313-7.

6. Boztug K, Appaswamy G, Ashikov A, et al. A syndrome with congenital neutropenia and mutations in G6PC3. N Engl J Med 2009;360:32-43.

7. Sinha S, Zhu QS, Romero G, Corey SJ. Deletional mutation of the external domain of the human granulocyte colony-stimulating factor receptor in a patient with severe chronic neutropenia refractory to granulocyte colonystimulating factor. J Pediatr Hematol Oncol 2003;25:791-6.

8. Barth PG, Wanders RJ, Vreken P, Janssen EA, Lam J, Baas F. X-linked cardioskeletal myopathy and neutropenia (Barth syndrome) (MIM 302060). J Inherit Metab Dis 1999;22:555-67.

9. Nagle DL, Karim MA, Woolf EA, et al. Identification and mutation analysis of the complete gene for Chediak-Higashi syndrome. Nat Genet 1996;14:307-11.

10. Huizing M, Scher CD, Strovel E, et al. Nonsense mutations in ADTB3A cause complete deficiency of the beta3A subunit of adaptor complex-3 and severe Hermansky-Pudlak syndrome type 2. Pediatr Res 2002;51:150-8.

11. Bohn G, Allroth A, Brandes G, et al. A novel human primary immunodeficiency syndrome caused by deficiency of the endosomal adaptor protein p14. Nat Med 2007;13:38-45.

12. Abdollahpour H, Appaswamy G, Kotlarz D, et al. The phenotype of human STK4 deficiency. Blood 2012;119:3450-7.

13. Vilboux T, Lev A, Malicdan MC, et al. A congenital neutrophil defect syndrome associated with mutations in VPS45. N Engl J Med 2013;369:5465.

14. Stepensky P, Saada A, Cowan M, et al. The Thr224Asn mutation in the VPS45 gene is associated with the congenital neutropenia and primary myelofibrosis of infancy. Blood 2013;121:5078-87.

15. Hernandez PA, Gorlin RJ, Lukens JN, et al. Mutations in the chemokine receptor gene CXCR4 are associated with WHIM syndrome, a combined immunodeficiency disease. Nat Genet 2003;34:70-4.

16. Boocock GR, Morrison JA, Popovic M, et al. Mutations in SBDS are associated with Shwachman-Diamond syndrome. Nat Genet 2003;33:97-101.

17. Kazenwadel J, Secker GA, Liu YJ, et al. Loss-of-function germline GATA2 mutations in patients with MDS/AML or MonoMAC syndrome and primary lymphedema reveal a key role for GATA2 in the lymphatic vasculature. Blood 2012;119:1283-91.

18. Horwitz MS, Corey SJ, Grimes HL, Tidwell T. ELANE mutations in cyclic and severe congenital neutropenia: genetics and pathophysiology. Hematol Oncol Clin North Am 2013;27:19-41, vii.

19. Carlsson G, Aprikyan AA, Tehranchi R, et al. Kostmann syndrome: severe congenital neutropenia associated with defective expression of Bcl-2, constitutive mitochondrial release of cytochrome $\mathrm{c}$, and excessive apoptosis of myeloid progenitor cells. Blood 2004;103:3355-61.

20. Massullo P, Druhan LJ, Bunnell BA, et al. Aberrant subcellular targeting of the G185R neutrophil elastase mutant associated with severe congenital neutropenia induces premature apoptosis of differentiating promyelocytes. Blood 2005;105:3397-404.

21. Köllner I, Sodeik B, Schreek S, et al. Mutations in neutrophil elastase causing congenital neutropenia lead to cytoplasmic protein accumulation and induction of the unfolded protein response. Blood 2006;108:493-500.

22. Grenda DS, Murakami M, Ghatak J, et al. Mutations of the ELA2 gene found in patients with severe congenital neutropenia induce the unfolded protein response and cellular apoptosis. Blood 2007;110:4179-87. 


\section{Mechanisms of inherited neutropenia $\quad$ Review}

23. Nanua S, Murakami M, Xia J, et al. Activation of the unfolded protein response is associated with impaired granulopoiesis in transgenic mice expressing mutant Elane. Blood 2011;117:3539-47.

24. Horwitz MS, Duan Z, Korkmaz B, Lee HH, Mealiffe ME, Salipante SJ. Neutrophil elastase in cyclic and severe congenital neutropenia. Blood 2007;109:1817-24.

25. Sakamoto C, Suzuki K, Hato F, et al. Antiapoptotic effect of granulocyte colony-stimulating factor, granulocyte-macrophage colony-stimulating factor, and cyclic AMP on human neutrophils: protein synthesis-dependent and protein synthesis-independent mechanisms and the role of the Janus kinase-STAT pathway. Int J Hematol 2003;77:60-70.

26. Souza LR, Silva E, Calloway E, Cabrera C, McLemore ML. G-CSF activation of AKT is not sufficient to prolong neutrophil survival. J Leukoc Biol 2013;93:883-93.

27. Kuijpers TW, Maianski NA, Tool AT, et al. Apoptotic neutrophils in the circulation of patients with glycogen storage disease type $1 \mathrm{~b}$ (GSD1b). Blood 2003;101:5021-4.

28. Jun HS, Lee YM, Song KD, Mansfield BC, Chou JY. G-CSF improves murine G6PC3-deficient neutrophil function by modulating apoptosis and energy homeostasis. Blood 2011;117:3881-92.

29. Clarke SL, Bowron A, Gonzalez IL, et al. Barth syndrome. Orphanet J Rare Dis 2013;8:23.

30. Schlame M, Acehan D, Berno B, et al. The physical state of lipid substrates provides transacylation specificity for tafazzin. Nat Chem Biol 2012;8:862-9.

31. KOSTMANN R. Infantile genetic agranulocytosis; agranulocytosis infantilis hereditaria. Acta Paediatr Suppl 1956;45:Suppl 105:1-78.

32. Klein C, Grudzien M, Appaswamy G, et al. HAX1 deficiency causes autosomal recessive severe congenital neutropenia (Kostmann disease). Nat Genet 2007;39:86-92.

33. Carlsson G, van't Hooft I, Melin M, et al. Central nervous system involvement in severe congenital neutropenia: neurological and neuropsychological abnormalities associated with specific HAX1 mutations. J Intern Med 2008;264:388-400.

34. Skokowa J, Klimiankou M, Klimenkova O, et al. Interactions among HCLS1, HAX1 and LEF-1 proteins are essential for G-CSF-triggered granulopoiesis. Nat Med 2012;18:1550-9.

35. Skokowa J, Cario G, Uenalan M, et al. LEF-1 is crucial for neutrophil granulocytopoiesis and its expression is severely reduced in congenital neutropenia. Nat Med 2006;12:1191-7.

36. Skokowa J, Welte K. LEF-1 is a decisive transcription factor in neutrophil granulopoiesis. Ann N Y Acad Sci 2007;1106:143-51.

37. Germeshausen M, Zeidler C, Stuhrmann M, Lanciotti M, Ballmaier M, Welte K. Digenic mutations in severe congenital neutropenia. Haematologica 2010;95:1207-10.

38. Andolina JR, Morrison CB, Thompson AA, et al. Shwachman-Diamond syndrome: diarrhea, no longer required? J Pediatr Hematol Oncol 2013;35:486-9.

39. Draptchinskaia N, Gustavsson P, Andersson B, et al. The gene encoding ribosomal protein S19 is mutated in Diamond-Blackfan anaemia. Nat Genet 1999;21:169-75.

40. Flygare J, Aspesi A, Bailey JC, et al. Human RPS19, the gene mutated in Diamond-Blackfan anemia, encodes a ribosomal protein required for the maturation of $40 \mathrm{~S}$ ribosomal subunits. Blood 2007; 109:980-6.

41. Pant V, Quintás-Cardama A, Lozano G. The p53 pathway in hematopoiesis: lessons from mouse models, implications for humans. Blood 2012;120:5118-27.

42. Farrar JE, Vlachos A, Atsidaftos E, et al. Ribosomal protein gene deletions in Diamond-Blackfan anemia. Blood 2011;118:6943-51.

43. Zhang Y, Wolf GW, Bhat K, et al. Ribosomal protein L11 negatively regulates oncoprotein MDM2 and mediates a p53-dependent ribosomal-stress checkpoint pathway. Mol Cell Biol 2003;23:8902-12.
44. Dutt S, Narla A, Lin K, et al. Haploinsufficiency for ribosomal protein genes causes selective activation of p53 in human erythroid progenitor cells. Blood 2011;117:2567-76.

45. Constantinou C, Elia A, Clemens MJ. Activation of p53 stimulates proteasome-dependent truncation of eIF4E-binding protein 1 (4E-BP1). Biol Cell 2008;100:279-89.

46. Deisenroth C, Zhang Y. Ribosome biogenesis surveillance: probing the ribosomal protein-Mdm2-p53 pathway. Oncogene 2010;29:4253-60.

47. Gazda HT, Preti M, Sheen MR, et al. Frameshift mutation in p53 regulator RPL26 is associated with multiple physical abnormalities and a specific pre-ribosomal RNA processing defect in diamond-blackfan anemia. Hum Mutat 2012;33:1037-44.

48. Menne TF, Goyenechea B, Sánchez-Puig N, et al. The Shwachman-BodianDiamond syndrome protein mediates translational activation of ribosomes in yeast. Nat Genet 2007;39:486-95.

49. Austin KM, Gupta ML Jr, Coats SA, et al. Mitotic spindle destabilization and genomic instability in Shwachman-Diamond syndrome. J Clin Invest 2008;118:1511-8.

50. Rujkijyanont P, Watanabe K, Ambekar C, et al. SBDS-deficient cells undergo accelerated apoptosis through the Fas-pathway. Haematologica 2008;93:363-71.

51. Ceci M, Gaviraghi C, Gorrini C, et al. Release of eIF6 (p27BBP) from the 60 S subunit allows 80 S ribosome assembly. Nature 2003;426:579-84.

52. Finch AJ, Hilcenko C, Basse N, et al. Uncoupling of GTP hydrolysis from eIF6 release on the ribosome causes Shwachman-Diamond syndrome. Genes Dev 2011;25:917-29.

53. Raaijmakers MH, Mukherjee S, Guo S, et al. Bone progenitor dysfunction induces myelodysplasia and secondary leukaemia. Nature 2010;464:852-7.

54. Dror Y, Freedman MH. Shwachman-Diamond syndrome: An inherited preleukemic bone marrow failure disorder with aberrant hematopoietic progenitors and faulty marrow microenvironment. Blood 1999;94:304854.

55. Barlow JL, Drynan LF, Trim NL, Erber WN, Warren AJ, McKenzie AN. New insights into 5q- syndrome as a ribosomopathy. Cell Cycle 2010;9:4286-93.

56. Johnson AW, Ellis SR. Of blood, bones, and ribosomes: is Swachman-Diamond syndrome a ribosomopathy? Genes Dev 2011;25:898-900.

57. Uyttebroeck A, Brock P, De Groote B, et al. 5q- syndrome in a child. Cancer Genet Cytogenet 1995;80:121-3.

58. Payne EM, Virgilio M, Narla A, et al. L-Leucine improves the anemia and developmental defects associated with Diamond-Blackfan anemia and $\operatorname{del}(5 \mathrm{q})$ MDS by activating the mTOR pathway. Blood 2012;120:2214-24.

59. Ebert BL, Pretz J, Bosco J, et al. Identification of RPS14 as a 5q- syndrome gene by RNA interference screen. Nature 2008;451:335-9.

60. Barlow JL, Drynan LF, Hewett DR, et al. A p53-dependent mechanism underlies macrocytic anemia in a mouse model of human $5 \mathrm{q}$ - syndrome. Nat Med 2010;16:59-66.

61. Starczynowski DT, Kuchenbauer F, Argiropoulos B, et al. Identification of miR-145 and miR-146a as mediators of the 5q- syndrome phenotype. Nat Med 2010;16:49-58.

62. Geering B, Simon HU. Peculiarities of cell death mechanisms in neutrophils. Cell Death Differ 2011;18:1457-69.

63. Ryno LM, Wiseman RL, Kelly JW. Targeting unfolded protein response signaling pathways to ameliorate protein misfolding diseases. Curr Opin Chem Biol 2013;17:346-52.

64. Duan Z, Horwitz M. Gfi-1 oncoproteins in hematopoiesis. Hematology 2003;8:339-44.

65. Moulding DA, Moeendarbary E, Valon L, Record J, Charras GT, Thrasher AJ. Excess F-actin mechanically impedes mitosis leading to cytokinesis failure in X-linked neutropenia by exceeding Aurora B kinase error correction capacity. Blood 2012;120:3803-11. 